\title{
Table des matières
}

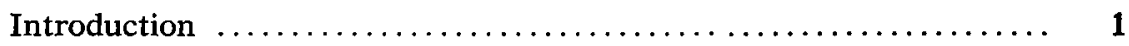

Chapitre I La personne: définitions et histoire du mot ...... 11

1. L'idée et le mot $\ldots \ldots \ldots \ldots \ldots \ldots \ldots \ldots \ldots \ldots, 11$

2. La personne dans le christianisme traditionnel .. 14

3. Personne et pensée moderne $\ldots \ldots \ldots \ldots \ldots \ldots, 17$

Chapitre II Fondements de l'anthropologie personnaliste ...... 30

1. Métaphysique de l'être ou métaphysique de la

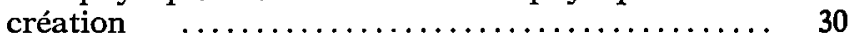

2. Matière et esprit : l'union de l'âme et du corps et l'individuation $\ldots \ldots \ldots \ldots \ldots \ldots \ldots \ldots \ldots \ldots, 38$

Chapitre III Individu et conscience de soi $\ldots \ldots \ldots \ldots \ldots \ldots . . \ldots 4$

1. Les facteurs constitutifs de l'individualité ..... 54

2. Conscience de soi et réflexion $\ldots \ldots \ldots \ldots \ldots \ldots, 67$

Chapitre IV De l'individu à la personne $\ldots \ldots \ldots \ldots \ldots \ldots \ldots . \quad 80$

1. L'individu comme sujet $\ldots \ldots \ldots \ldots \ldots \ldots \ldots, 80$

2. L'individu comme être objectivé .......... 89

3. Personne et vocation $\ldots \ldots \ldots \ldots \ldots \ldots \ldots \ldots, 95$

Chapitre V Nature et origine de l'opposition entre l'individu et la personne ............................ 104

1. La distinction individu-personne chez Mounier .. 104

2. Origine et signification de l'opposition individu-

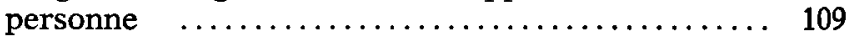

Chapitre VI Personne, société et communauté ............ 120

1. Origine de la distinction société-communauté .... 121

2. Communauté, groupement réel ............ 124

3. Communauté, forme de sociabilité $\ldots \ldots \ldots \ldots \ldots 127$

4. Personne et humanité $\ldots \ldots \ldots \ldots \ldots \ldots \ldots, 131$

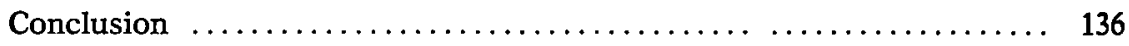

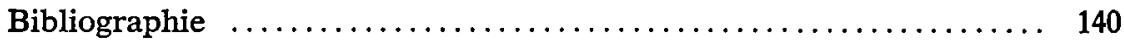

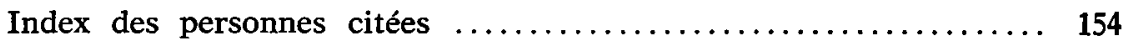

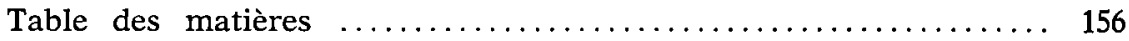


IMPRIMERIE LUSSAUD - 388

85 - Fontenay-le-Comte

Dépôt légal 1'r trımestre 1972

Imprimeur $n^{\circ} 1254$ 
